\title{
Analysis of Vehicle Handing Stability Based on Orthogonal Test
}

\author{
Qian Run-Hua 1, a, Lei Zhi-Ping 2, b, Tang Guo-Dong ${ }^{3, c}$ \\ 1,2 Department of Mechanical Engineering, \\ Army Academy of Armored Forces, Beijing 100072, China. \\ ${ }^{3}$ Department of Optical Engineering, \\ The Army Infantry Academy of PLA, Shijiazhuang 050200, China. \\ a,b Email: 664607015@qq.com \\ cEmail: 2912265054@qq.com
}

Keyword: handing stability; Orthogonal test; simulation experiment.

Abstract: Quadrature scheme is a scientific method of arranging multi-factors and multi-standards, because it can get enough experiment information with less experiment times, so it is suitable for multi-factor and multi-level experiments. In this paper, the orthogonal test method is adopted to design the test scheme to analyze the influence of vehicle quality and driving speed on vehicle handing stability. And the order and contribution rate of every experiment factor on target index is determined by means of range analysis and ANOVA analysis respectively. So this paper provides a reference for the study of the influence factors of multi-axis vehicle steering stability [1].

\section{Introduction}

With the rapid development of the transportation industry, the vehicles overload is coming from bad to worse. The problem of traffic safety is becoming more and more serious, caused by traffic accident. People's Casualties and property losses are also growing. So people are looking at car comfort. As well as the economy, it also turned more attention to the safety of cars.

Introduction to orthogonal test. Orthogonal design is also called orthogonal design, which is arranged scientifically by orthogonal table. The method of multi - factor test is one of the most commonly used experimental design methods. It is based on the orthogonal method to select some representative points from the comprehensive test which have the characteristics of "uniform dispersion, homogeneous and comparable". So orthogonal test design is the main method of fractional factorial design, which is an efficient, fast and economical experimental design method. And it has been widely used in many fields.

\section{Scheme Design and Test}

There are many factors that influence the handing stability of the vehicle during the analysis of the stability of the vehicle Such as the quality of the vehicle, the vehicle barycenter position, the stiffness of the tire, the stiffness and damping of the suspension, the speed of the car, and the mass and position of axles, etc [4]. Because this article is to analyze how the vehicle handling stability performance change when the three-axis truck loading of the goods, so the vehicle mass center of total quality, the $\mathrm{x}$ coordinate and the $\mathrm{y}$ coordinate of the center of the vehicle mass and the vehicle speed are considered as experimental factors, they are recorded as A, B, C and D and Each factor is divided into three levels [2]. The values of each influencing factor are shown in table 1. 
Table 1: Test factors and Test level values

\begin{tabular}{c|cccc}
\hline \multirow{2}{*}{$\begin{array}{c}\text { Test } \\
\text { level }\end{array}$} & $\mathrm{A}$ & \multicolumn{3}{|c}{ The test factors } \\
\cline { 2 - 5 } & Mass[kg] & $\begin{array}{c}\text { The distance between } \\
\text { center of mass and } \\
\text { front axles[m] }\end{array}$ & $\begin{array}{c}\text { The z-coordinate } \\
\text { of barycenter }[\mathrm{m}]\end{array}$ & Vehicle speed [m/s] \\
\hline 1 & 15000 & 4.3448 & 0.615 & 15.5 \\
2 & 13500 & 3.91032 & 0.5535 & 13.95 \\
3 & 16500 & 4.77928 & 0.6765 & 17.05 \\
\hline
\end{tabular}

Now We will study the influence degree of four factors on vehicle control stability by the orthogonal test in four factors and three levels. First, we should select a proper orthogonal test table. Because there are 4 influencing factor and 3 level, we can choose the orthogonal table $L_{9}\left(3^{4}\right)$ or $L_{27}\left(3^{13}\right)$.In addition, the effect of four factors on vehicle handing stability is analyzed without considering the interaction between factors, so $L_{9}\left(3^{4}\right)$ orthogonal table was Chosen.

Table 2: Schemes to experiment

\begin{tabular}{|c|c|c|c|c|c|c|}
\hline \multirow{3}{*}{ Test Number } & \multicolumn{6}{|c|}{ Factor } \\
\hline & A & \multicolumn{3}{|c|}{ B } & $\mathrm{C}$ & $\mathrm{D}$ \\
\hline & Mass & \multicolumn{3}{|c|}{$\begin{array}{l}\text { The } \mathrm{x} \text {-coordinate of } \\
\text { the center of mass }\end{array}$} & $\begin{array}{l}\text { The z-coordinate of } \\
\text { the center of mass }\end{array}$ & Vehicle speed \\
\hline 1 & 15000 & 4.3448 & 0.9505 & 2.2505 & 0.615 & 15.5 \\
\hline 2 & 15000 & 3.91032 & 1.38498 & 2.68498 & 0.5535 & 13.95 \\
\hline 3 & 15000 & 4.77928 & 0.51602 & 1.81602 & 0.6765 & 17.05 \\
\hline 4 & 13500 & 4.3448 & 0.9505 & 2.2505 & 0.5535 & 17.05 \\
\hline 5 & 13500 & 3.91032 & 1.38498 & 2.68498 & 0.6765 & 15.5 \\
\hline 6 & 13500 & 4.77928 & 0.51602 & 1.81602 & 0.615 & 13.95 \\
\hline 7 & 16500 & 4.3448 & 0.9505 & 2.2505 & 0.6765 & 13.95 \\
\hline 8 & 16500 & 3.91032 & 1.38498 & 2.68498 & 0.615 & 17.05 \\
\hline 9 & 16500 & 4.77928 & 0.51602 & 1.81602 & 0.5535 & 15.5 \\
\hline
\end{tabular}

Taking three-axle vehicle as an example, after establishing the 3-DOF dynamic differential equation, Simulink software is used to establish its simulation model, as shown in figure 1. According to the Experiment Scheme shown as table 2, The steady-state value of the sideslip angle of vehicle, the yaw rate, the vehicle roll angle and the lateral acceleration of the vehicle are used as the evaluation index. The experimental results are shown in table 3. 


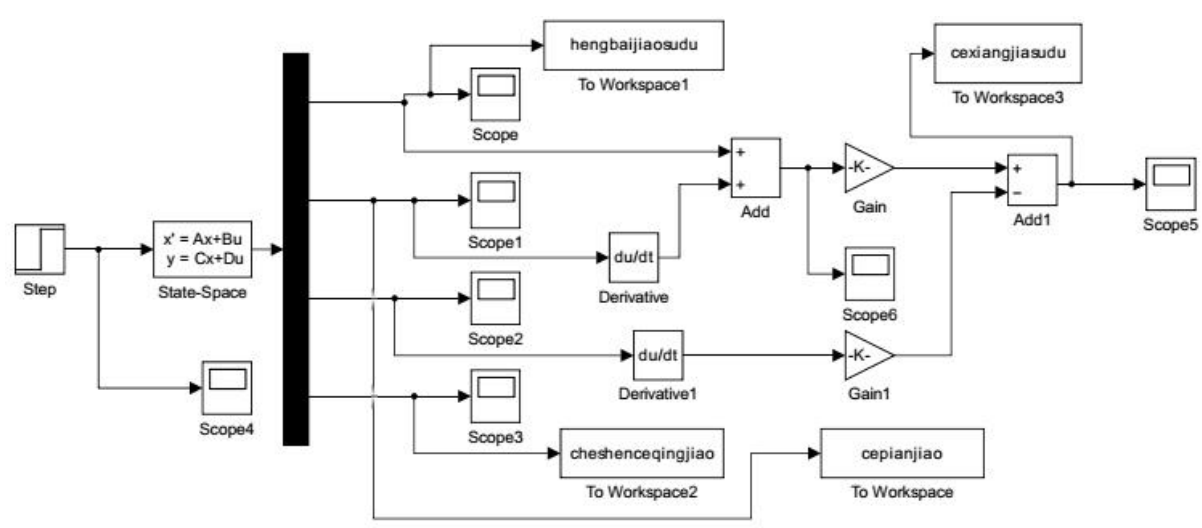

Figure 1: Model of simulation test established by Simulink.

Table 3: Test Results

\begin{tabular}{ccccc}
\hline Test Number & \multicolumn{3}{c}{ Test Results } \\
\hline & $\begin{array}{c}\text { sideslip angle of } \\
\text { vehicle }\end{array}$ & yaw rate & $\begin{array}{c}\text { vehicle roll } \\
\text { angle }\end{array}$ & lateral acceleration \\
\hline 1 & 0.3992 & 9.194 & 0.867 & 1.584 \\
2 & 0.7792 & 7.884 & 0.5989 & 1.222 \\
3 & -0.05929 & 10.89 & 1.249 & 2.063 \\
4 & 0.3478 & 10.16 & 0.8366 & 1.925 \\
5 & 0.733 & 8.761 & 0.8099 & 1.508 \\
6 & 0.2654 & 8.485 & 0.639 & 1.317 \\
7 & 0.4616 & 8.239 & 0.8623 & 1.728 \\
8 & 0.5126 & 9.607 & 1.11 & 1.82 \\
9 & 0.01779 & 9.789 & 0.9192 & 1.688 \\
\hline
\end{tabular}

\section{Analysis of orthogonal test results}

According to the orthogonal table characteristics, the test conditions of test number 1,2 and 3 are exactly the same for A factor, so we can compare the test results of test Numbers 1, 2 and 3 directly. If factor A does not affect the test target, then we can see $k_{A 1} \approx k_{A 2} \approx k_{A 3}$ [4]. However, the calculation results show that $k_{A 1} 、 k_{A 2} 、 k_{A 3}$ are not equal. which indicates that $\mathrm{A}$ has influence on the test results.so According to the size of $k_{A 1} 、 k_{A 2} 、 k_{A 3}$, the influence of A on the test results is judged. We can see from the table that $k_{A 1}<k_{A 2}<k_{A 2}$, it indicates that as the mass of the vehicle increases, the sideslip Angle of the vehicle's barycenter becomes smaller. Similarly, the effects of A, B, C and D on other test result can be analyzed by the same method。The order and contribution rate of every experiment factor on target index is determined by means of range analysis and ANOVA analysis respectively. The greater the rang indicates that the influence of this factor on the test result is greater.

And It can be seen from table 4 that there is a strong correlation between vehicle handing stability and factor D for it has the greatest rang in the three test results [3]. At the same time, it can be seen that as the vehicle speed increases, the yaw rate of the vehicle, the vehicle roll angle, the lateral acceleration of the vehicle will be larger, the sideslip angle of vehicle will be smaller, and the 
handing stability of the vehicle will become bad. Therefore, when the vehicle makes a turn, the vehicle should reduce the driving speed to keep it in good handing stability.

$\mathrm{B}$ factor has a significant influence on vehicle handing stability.it has a great influence on sideslip angle of vehicle and yaw rate of the velocity [4]. Furthermore, the handing stability of the vehicle is better when the center is close to the front axle. As a result, the heavy cargo should be placed in the front of the van to make the vehicle center as close as possible to the front axle. And B factors have little effect on vehicle roll angle.

The influence of A factor on vehicle handing stability is mainly manifested that as the quality of the cargo increases, the sideslip angle, the yaw rate and lateral acceleration of vehicle become larger. so when the vehicle is loaded, it should strictly avoid the situation of overload.

$\mathrm{C}$ factor has a great influence on the side tilt of the vehicle and the higher the center of vehicle mass, the larger vehicle roll angle, the easier it is to roll over, when vehicle make the turn. Therefore, it is not advisable to Put heavy cargo on top when loading the goods

Table 4: Results analysis

\begin{tabular}{|c|c|c|c|c|c|}
\hline & & $\mathrm{A}$ & B & $\mathrm{C}$ & $\mathrm{D}$ \\
\hline \multirow{7}{*}{$\begin{array}{l}\text { sideslip } \\
\text { angle } \\
\text { of vehicle }\end{array}$} & $\mathrm{K} 1$ & 1.11911 & 1.2086 & 1.1772 & 1.14999 \\
\hline & $\mathrm{K} 2$ & 1.3462 & 2.0248 & 1.14479 & 1.5062 \\
\hline & $\mathrm{K} 3$ & 0.99199 & 0.2239 & 1.13531 & 0.80111 \\
\hline & $\mathrm{k} 1$ & 0.37303667 & 0.402866667 & 0.3924 & 0.38333 \\
\hline & $\mathrm{k} 2$ & 0.44873333 & 0.674933333 & 0.38159667 & 0.502066667 \\
\hline & $\mathrm{k} 3$ & 0.33066333 & 0.074633333 & 0.37843667 & 0.267036667 \\
\hline & Rang & 0.11807 & 0.6003 & 0.01396333 & 0.23503 \\
\hline \multirow{7}{*}{ yaw rate } & $\mathrm{K} 1$ & 27.968 & 27.593 & 27.286 & 27.744 \\
\hline & $\mathrm{K} 2$ & 27.406 & 26.252 & 27.833 & 24.608 \\
\hline & $\mathrm{K} 3$ & 27.635 & 29.164 & 27.89 & 30.657 \\
\hline & $\mathrm{K} 1$ & 9.32266667 & 9.197666667 & 9.09533333 & 9.248 \\
\hline & $\mathrm{k} 2$ & 9.13533333 & 8.750666667 & 9.27766667 & 8.202666667 \\
\hline & $\mathrm{k} 3$ & 9.21166667 & 9.721333333 & 9.29666667 & 10.219 \\
\hline & Rang & 0.111 & 0.970666667 & 0.20133333 & 2.016333333 \\
\hline \multirow{7}{*}{$\begin{array}{l}\text { vehicle roll } \\
\text { angle }\end{array}$} & $\mathrm{K} 1$ & 2.7149 & 2.5659 & 2.616 & 2.5961 \\
\hline & $\mathrm{K} 2$ & 2.2855 & 2.5188 & 2.3547 & 2.1002 \\
\hline & $\mathrm{K} 3$ & 2.8915 & 2.8072 & 2.9212 & 3.1956 \\
\hline & $\mathrm{K} 1$ & 0.90496667 & 0.8553 & 0.872 & 0.865366667 \\
\hline & $\mathrm{k} 2$ & 0.76183333 & 0.8396 & 0.7849 & 0.700066667 \\
\hline & $\mathrm{k} 3$ & 0.96383333 & 0.935733333 & 0.97373333 & 1.0652 \\
\hline & Rang & 0.202 & 0.096133333 & 0.18883333 & 0.365133333 \\
\hline \multirow{7}{*}{$\begin{array}{c}\text { lateral } \\
\text { acceleration }\end{array}$} & $\mathrm{K} 1$ & 4.869 & 5.237 & 4.721 & 4.78 \\
\hline & $\mathrm{K} 2$ & 4.75 & 4.55 & 4.835 & 4.267 \\
\hline & K3 & 5.236 & 5.068 & 5.299 & 5.808 \\
\hline & $\mathrm{K} 1$ & 1.623 & 1.745666667 & 1.57366667 & 1.593333333 \\
\hline & $\mathrm{k} 2$ & 1.58333333 & 1.516666667 & 1.61166667 & 1.422333333 \\
\hline & $\mathrm{k} 3$ & 1.74533333 & 1.689333333 & 1.76633333 & 1.936 \\
\hline & Rang & 0.162 & 0.229 & 0.19266667 & 0.513666667 \\
\hline \multirow{4}{*}{\multicolumn{2}{|c|}{$\begin{array}{l}\text { Primary and } \\
\text { secondary order }\end{array}$}} & \multirow{4}{*}{\multicolumn{2}{|c|}{$\begin{array}{l}\text { sideslip angle of vehicle } \\
\text { yaw rate } \\
\text { vehicle roll angle } \\
\text { lateral acceleration }\end{array}$}} & \multicolumn{2}{|c|}{$\mathrm{B}>\mathrm{D}>\mathrm{A}>\mathrm{C}$} \\
\hline & & & & \multicolumn{2}{|c|}{$\mathrm{D}>\mathrm{B}>\mathrm{C}>\mathrm{A}$} \\
\hline & & & & \multicolumn{2}{|c|}{$D>A>C>B$} \\
\hline & & & & \multicolumn{2}{|c|}{$\mathrm{D}>\mathrm{B}>\mathrm{C}>\mathrm{A}$} \\
\hline
\end{tabular}




\section{Conclusions}

1. In this paper, the experimental scheme to study the influence of vehicle quality and speed on the control stability of vehicle is designed by orthogonal test method. Computer simulation of influences of vehicle speed, mass of the whole vehicle and position of the gravity center upon the handing stability is carried out. Finally, analyses the influencing degree of each factor on the handing stability by the orthogonal experiment.

2. The experimental results show that the yaw rate, vehicle roll angle, lateral acceleration of the vehicle is the most affected by the vehicle speed. The distance between the center of vehicle mass and the front axle of vehicle has a very important influence on sideslip angle of vehicle [5].

3. In the process of actual automobile design, the control stability test of automobile is a multi-factor test, and the level of each factor is relatively large, but using orthogonal test design method can simplify test times and shorten automobile test cycle.

\section{Acknowledgements}

This work was financially supported by Weapons and equipment military research projects of the PLA (WG2015ZT020001).

\section{References}

[1] H. Zhang, X.X. Guo and B. Yang: Simulation And Analysis of Truck Steering Returnability Based on Orthogonal Tests, Machinery Design and Manufacture Vol 2013-5, p. 137-139.

[2] Y.W. Cui and C.H. Du : Application of thought on the probability theory and mathematical statistics. Journal of Henan Mechanical and Electrical Engineering College Vol. 2004, 12-2, p. 61-63.

[3] C. Huang, L. Chen, H.B. Jiang and CH. CH. Yuan: Relationship between vehicle yaw velocity and heeling angle under steady state. Transactions of the Chinese Society for Agricultural Machinery Vol. 2014-45(2), p. 34-39.

[4] Y.B. Yan, Y.N. Zhang, NM. Yan, and BL. Han: Simulation Study of Motion Control Algorithm for a Six-wheel Independent Drive Skid-steering Vehicle. Acta Armamentarii Vol. 34-11(2013), p. 1461-1468.

[5] Zh.F. Li, P. Ji, and X.L. Li: SUV Rollover Performance Simulation Analysis Based on the Orthogonal Array, Machinery Design and Manufacture Vol. 2014-12 p. 251-254. 